\title{
Overexpression of Large- Conductance Calcium-Activated Potassium Channels in Human Glioblastoma Stem-Like Cells and Their Role in Cell Migration
}

\author{
PAOLO ROSA,' LUIGI SFORNA, ' SILVIA CARLOMAGNO,' GIORGIO MANGINO,' \\ MASSIMO MISCUSI,' MAURO PESSIA, ${ }^{3,4}$ FABIO FRANCIOLINI, ${ }^{2}$ ANTONELLA CALOGERO, ${ }^{\prime *}$ \\ AND LUIGI CATACUZZENO ${ }^{2 * *}$ \\ 'Department of Medico-Surgical Sciences and Biotechnologies, "La Sapienza" University, Latina, Italy \\ ${ }^{2}$ Department of Chemistry Biology and Biotechnology, University of Perugia, Perugia, Italy \\ ${ }^{3}$ Department of Experimental Medicine, University of Perugia, Perugia, Italy \\ ${ }^{4}$ Department of Physiology and Biochemistry, University of Malta, Msida, Malta
}

\begin{abstract}
Glioblastomas (GBMs) are brain tumors characterized by diffuse invasion of cancer cells into the healthy brain parenchyma, and establishment of secondary foci. GBM cells abundantly express large-conductance, calcium-activated potassium (BK) channels that are thought to promote cell invasion. Recent evidence suggests that the GBM high invasive potential mainly originates from a pool of stem-like cells, but the expression and function of BK channels in this cell subpopulation have not been studied. We investigated the expression of BK channels in GBM stem-like cells using electrophysiological and immunochemical techniques, and assessed their involvement in the migratory process of this important cell subpopulation. In U87-MG cells, BK channel expression and function were markedly upregulated by growth conditions that enriched the culture in GBM stem-like cells (U87-NS). Cytofluorimetric analysis further confirmed the appearance of a cell subpopulation that co-expressed high levels of BK channels and CDI33, as well as other stem cell markers. A similar association was also found in cells derived from freshly resected GBM biopsies. Finally, transwell migration tests showed that U87-NS cells migration was much more sensitive to BK channel block than U87-MG cells. Our data show that BK channels are highly expressed in GBM stem-like cells, and participate to their high migratory activity.
\end{abstract}

J. Cell. Physiol. 9999: I-II, 2016. (C) 2016 Wiley Periodicals, Inc.

Gliomas are major tumors involving glial cells in the central nervous system, accounting for $35-50 \%$ of intracranial tumors in adults. Among them, grade IV glioblastoma (GBM) has the highest incidence and shortest patient survival of all brain tumors. Currently, patients undergoing standard intervention, consisting of gross surgical resection followed by radiotherapy and chemotherapy, present an overall median survival of about 20 months. Great efforts are therefore made to identify new molecular biomarkers in gliomas that enable a personalized therapy of this highly heterogeneous tumor (Holland, 200I; Eckel-Passow et al., 20I5; Wang et al., 20I5). The poor prognosis of GBM is mainly caused by the diffuse invasion of GBM cells into the healthy brain parenchyma, that makes full surgical resection essentially impossible and radiation therapy ineffectual (Maher et al., 200 I). Understanding the mechanism of GBM cell migration and invasion is thus a key step to improve the therapy against this tumor.

Several properties of cancers, including GBM, are influenced by the dysregulation of ion channel expression and function (Sontheimer, 2008; Catacuzzeno et al., 2012, 20I4; Sforna et al., 20I5). One of the most studied dysregulated ion channels in GBM cells is the large-conductance, calcium-activated $\mathrm{K}$ (BK) channel, gated by the concerted action of both voltage and intracellular calcium (Turner and Sontheimer, 20I4). BK channels are structurally made by the association of four poreforming $\alpha$ subunits, coded by only one gene (the KCNMAI) whose transcript can undergo different splicing processes (Kyle and Braun, 2014). Notably, when compared to normal astrocytes, GBM cells overexpress a particular splicing isoform of the BK channel (the glioma BK, gBK; Liu et al., 2002). Moreover, modulatory $B$ subunits $(\beta I-\beta 4)$ can associate with the BK channel $\alpha$ subunits and increase the channel's functional diversity in terms of activation and deactivation kinetics,

Paolo Rosa and Luigi Sforna have equally contributed to this work.

Contract grant sponsor: MIUR-PRIN;

Contract grant number: 20108WT59Y.004.

Contract grant sponsor: Ministero della Salute;

Contract grant number: GR-2009-1580433.

Contract grant sponsor: Fondazione Cassa di Risparmio di Perugia;

Contract grant numbers: 2012. 0240.02I, 2014/222I.

*Correspondence to: Antonella Calogero, Department of MedicoSurgical Sciences and Biotechnologies, "La Sapienza" University, Polo Pontino-Corso della Repubblica 79, Latina 04100, Italy. E-mail: antonella.calogero@uniromal.it

**Correspondence to: Luigi Catacuzzeno, Department of Chemistry Biology and Biotechnology Via Pascoli I, Perugia 06123, Italy. E-mail: luigi.catacuzzeno@unipg.it

Manuscript Received: 16 February 2016

Manuscript Accepted: 7 September 2016

Accepted manuscript online in Wiley Online Library (wileyonlinelibrary.com): 00 Month 2015.

DOI: $10.1002 /$ jcp. 25592 
voltage-dependence, inactivation, and calcium sensitivity (Torres et al., 20l4). Among them, the $\beta 4$ is by far the most abundantly expressed in the brain (Weiger et al., 2000), and the only one detected in GBM cells (Bednarczyk et al., 20I3). In GBM cells BK channels, working in concert with $\mathrm{Cl}$ channels, promote transmembrane ion and water fluxes, critical for cell volume and membrane potential changes, ultimately leading to cell proliferation, migration, or death (Cuddapah and Sontheimer, 20II). More specifically, BK channels have been found to be involved in GBM migration through restricted extracellular spaces, as well as in two-dimensional migration promoted by menthol (Weaver et al., 2006; Catacuzzeno et al., $2015)$. In addition, ionizing radiation promoted $\left[\mathrm{Ca}^{2+}\right]_{i}$ increases and $\mathrm{BK}$ channels activation, ultimately leading to GBM cell migration (Steinle et al., 20 I I). All these data point to a key role of $B K$ channels in the migration/invasion of GBM cells.

Recent evidence suggests that in several cases GBM originates from a pool of stem-like cells that share properties in common with neuronal stem cells, being capable of extensive proliferation, self-renewal, and multi-lineage differentiation (Maugeri-Saccà et al., 20I3). Many data show that the stemness behavior of GBM cells closely associates with an increased aggressiveness and with the resistance to current anticancer therapies, such as chemo- and radiotherapy (Bao et al., 2006; Maugeri-Saccà et al., 20I I). Most notably, GBM stem-like cells also possess a greater invasive potential than non-stem tumor cells (Inoue et al., 20 I0; Wu et al., 20 I I; Chen et al., 20I3), but the mechanism leading to this increased invasiveness is still unclear. Based on these data we set out to investigate whether the BK channels are expressed in GBM stem-like cells and are involved in their migratory process.

\section{Materials and Methods \\ Cell culture}

U87-MG GBM cell line was purchased from American Type Culture Collection (Manassas, VA) and was grown in DMEM-FI2 supplemented with $10 \%$ heat-inactivated fetal bovine serum (Sigma-Aldrich St. Louis, MO), $100 \mathrm{IU} / \mathrm{ml}$ penicillin G, $100 \mu \mathrm{g} / \mathrm{ml}$ streptomycin, I\% L-glutamine, I\% nonessential amino acids, and I $\mathrm{mM}$ sodium pyruvate at $37^{\circ} \mathrm{C}$ in a $5 \% \mathrm{CO}_{2}$-humidified atmosphere. The medium was changed twice a week, and the cells were subcultured when confluent. U87 neurospheres (U87-NS) were derived from U87-MG by growing them in serum-free DMEM-FI 2 supplemented with $20 \mathrm{ng} / \mathrm{ml}$ bFGF, $20 \mathrm{ng} / \mathrm{ml}$ EGF (PeproTech, Rocky Hill, NJ) B-27, and N2 supplements (Life Technologies, Carlsbad, CA) for up to 3 weeks. Neurospheres were cultured for at least 10 days and before each experiment the enrichment in $\mathrm{CDI} 33^{+}$cells was evaluated by flow cytometry. GBM primary cultures (WHO grade IV) were obtained in a previous work by our group from tumor specimens of patients (Calogero et al., 200I). For electrophysiological experiments shown in Figure I, cells were seeded in Petri dishes at 30,000 cells $/ \mathrm{ml}$ and used after $3 \mathrm{~h}$. For electrophysiological experiments shown in Figures 2 and 6, cells were seeded in Petri dishes at 50,000 cells $/ \mathrm{ml}$ and used after $3 \mathrm{~h}$.

\section{Electrophysiology}

The whole-cell dialyzed configuration was used for electrophysiological recordings from GBM cells (Fioretti et al., 2006; Sforna et al., 2016). Currents-voltages were amplified with a HEKA EPC- 10 amplifier (List Medical, Darmstadt, Germany), and analyzed with the Patch-Master package (version $2 \times 69$, HEKA ELEKTRONIK) and Microcal Origin 8.0 software. For on-line data collection, macroscopic currents were filtered at $3 \mathrm{kHz}$ and sampled at $200 \mu \mathrm{s} /$ point. The external solution contained (in $\mathrm{mM}$ ):

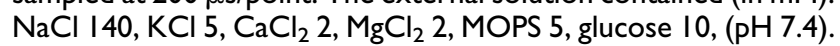

Octanol (I mM) was added to the external bathing solution to block gap-junctions (Eskandari et al., 2002; Catacuzzeno et al., 20II). TRAM-34 (3 $\mu \mathrm{M})$ was added to block $\mathrm{Ca}^{2+}$-activated intermediate-conductance $\mathrm{K}$ channels, expressed in these cells. The internal solution contained: $\mathrm{KCl}$ I55, EGTA-K I, MOPS 5, $\mathrm{MgCl}_{2}$ I ( $\left.\mathrm{pH} 7.2\right)$. Access resistances ranging between 4-8M $\Omega$ were actively compensated to ca. $50 \%$. All chemicals used were of analytical grade. Dimethyl sulfoxide (DMSO),

tetraethylammonium chloride (TEA), I,3-Dihydro-I-[2-hydroxy5-(trifluoromethyl) phenyl]-5-(trifluoromethyl)-2H-benzimidazol2-one (NSI619), were purchased from Sigma-Aldrich. Paxilline and iberiotoxin were purchased from Alomone Labs (Jerusalem, Israel). I-[(2-Chlorophenyl) diphenylmethyl]-IH-pyrazole (TRAM-34) was from Tocris Bioscience (Avonmouth, UK). TRAM-34, NSI69, and paxilline were prepared in DMSO (at concentrations of 10,10 , and $5 \mathrm{mM}$, respectively). The maximal DMSO concentration in the recording solutions was $0.1 \%$. We verified that application of $0.1 \%$ DMSO did not have significant effects on the membrane currents of U87-MG cells (data not shown). The pharmacological agents were dissolved daily in the appropriate solution at the concentrations stated, and bath applied with a gravity perfusion system. Experiments were carried out at room temperature $\left(18-22^{\circ} \mathrm{C}\right)$. Data are presented as mean $\pm \mathrm{SE}$. Statistical differences between experimental groups were verified by using the $t$-test, and considering a level of significance $(P)$ of 0.05 .

\section{RNA extraction and real time PCR}

Cellular and tissue mRNA was isolated using RNeasy Mini kit (Qiagen, Hilden, Germany) according to the manufacturer's instructions. To extract RNA, cultured cells were grown in a 60-mm dish to $60-80 \%$ confluency and lysed. mRNA concentration was quantified using a DU 800 Spectrophotometer (Beckman Coulter, Indianapolis, IN). One microgram of mRNA was converted to cDNA using the High Capacity cDNA Reverse Transcription Kit (Applied Biosystem, CA) according to the manufacturer's instructions. Gene expression was quantified by real-time PCR using the 7900HT Fast Real-time PCR System and Power SYBR Green PCR Master Mix (Applied Biosystem, Warrington, UK) according to the manufacturer's instructions and analyzed. Each experiment was performed in triplicate and is expressed as mean \pm SD. Experiments were independently repeated three times. Gene expression levels were quantified from real-time PCR data by the comparative threshold cycle (CT) method using $18 \mathrm{~S}$ as an internal control gene. The housekeeping gene $18 \mathrm{~S}$ was used as internal reference. The following genespecific primers were used: human KCNMAI (QuantiTect Primer Assay, QT00024I57, Qiagen); human KCNMBI FW 5'CTGTACCACACGGAGGACACT-3', RV 5'GTAGAGGCGCTGGAATAGGAC-3'; human KCNMB2 FW 5'CACTGAAGGCAGGAGAGGAC-3', RV $5^{\prime}$ GAGACTCTTCGGTCCACACG-3'; human KCNMB3 FW 5'GAGAGGACCGAGCCGTGATG-3', RV 5'CACCACCTAGCAGAGTCAGTGAAG-3'; human KCNMB4 FW 5'-GCGTTCTCATTGTGGTCC-3', RV 5'TTCCAGTTGTGCCTGTTTC-3'.

\section{Western blot}

Cells were lysed in RIPA buffer $(50 \mathrm{mM}$ Tris- $\mathrm{HCl}$ pH 8.0, I50 mM $\mathrm{NaCl}, \mathrm{I} \%$ Nonidet $\mathrm{P}-40$, I mM EDTA, $0.5 \%$ sodium deoxycholate, $0.1 \%$ SDS) with protease inhibitors, I mM PMSF, I mM DTT, and $0.5 \mathrm{mM}$ sodium orthovanadate (Sigma-Aldrich). Protein concentration was determined by the Bradford assay and $40 \mu \mathrm{g}$ of proteins per sample were resolved on an $8 \%$ SDS-PAGE gel and blotted onto a PVDF membrane (Amersham HyBond-P GE Healthcare, UK). After blocking at RT in 5\% dry-milk in TBS containing $0.1 \%$ Tween-20 for I h, membranes were incubated overnight at $4^{\circ} \mathrm{C}$ with rabbit polyclonal anti-CDI33 antibody 


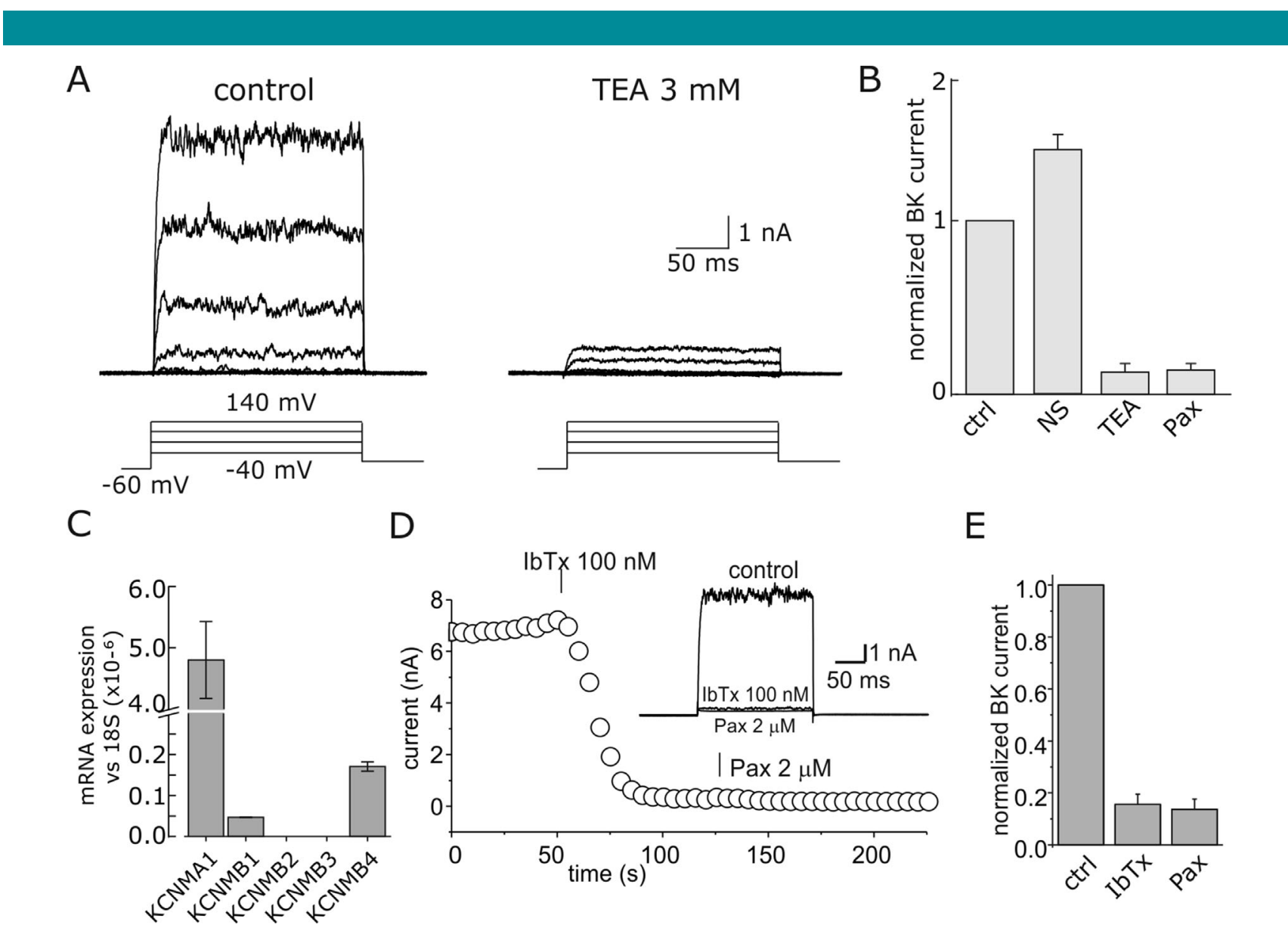

Fig. I. Expression of BK channels in U87-MG GBM cells. (A) Current traces obtained in response to depolarizing steps from -40 to $+140 \mathrm{mV}$ from a holding potential of $-60 \mathrm{mV}$ from a GBM cell held under the ionic conditions described in the text, in control conditions and after bath application of $3 \mathrm{mM}$ TEA. (B) Bar plot showing the mean residual current recorded after bath application of TEA (3 mM), Pax ( $2 \mu \mathrm{M})$ e NSI6 $19(20 \mu M)$. (C) mRNA expression levels (vs. the I8S transcript) of the KCNMAI and the four KCNMB transcripts in U87-MG cell line. (D) Time course of the BK current at $+120 \mathrm{mV}$ showing the effect of successive application of $100 \mathrm{nM}$ IbTx and $2 \mu M$ paxilline. Inset: Current traces obtained in control, lbtx and IbTx + Pax for the same experiment shown in the main panel. (E) Plot showing the mean residual current after IbTx and IbTx + Pax, assessed in six experiments similar to that shown in panel D.

(dilution I:500, abcam 19898), and mouse monoclonal anti- $\beta$-actin (dilution I:2000) antibody was used for normalization. Membranes were then incubated with anti-rabbit and anti-mouse horseradish peroxidase conjugated secondary antibodies (dilution I: I0000, GE Healthcare Bio-Sciences, Piscataway, NJ). Immunocomplexes were detected by ECL Western Blotting detection system (GE Healthcare Bio-Sciences). Densitometric analysis was performed with Image Studio software (LI-COR Biosciences, Lincoln, NE).

\section{Cytometric analysis and cell sorting}

Biparametric analysis was performed by BK/AlexaFluor 488 indirect staining followed by CDI33/PE direct staining. Briefly, U87-MG cells and neurospheres derived thereof (U87-NS) were collected, washed, and resuspended in PBS, $2 \%$ FCS $\left(10^{6}\right.$ cells/ $100 \mu \mathrm{l})$. Samples were incubated for $30 \mathrm{~min}$ at $4^{\circ} \mathrm{C}$ with $10 \mu \mathrm{l}$ of anti-BK (APC-I5I, Alomone Labs), washed and resuspended again in $100 \mu \mathrm{l}$ of PBS, $2 \%$ FBS. AlexaFluor 488-conjugated mouse antirabbit antibody (final dilution I:250, A I 1034, Life Technologies) was then added and the samples were incubated for additional $30 \mathrm{~min}$ at $4^{\circ} \mathrm{C}$. After an additional wash cells were stained for $30 \mathrm{~min}$ at $4^{\circ} \mathrm{C}$ using $10 \mu \mathrm{l}$ of an anti-CD I 33-PE antibody (CD I 33/2, clone 293C, Miltenyi Biotech, Calderara di Reno, Italy). At the end of incubation, cells were washed again, resuspended in PBS, $2 \%$ FBS, and the samples were acquired on a FACs ARIA II instrument using FACs DiVa software (v.6.I.I, both by Becton Dickinson, Milan, Italy). At least 20,000 events were recorded and analyzed using Flowing software (v2.5.I, Turku Centre for Biotechnology, Finland).

For the sorting of BK-enriched U87-NS population, cells were stained as previously reported then washed and resuspended in PBS, $2 \%$ FBS. Both BK-rich and BK-basal subpopulations were isolated using FACs ARIA II and FACs DiVa software, then they were checked again for $B K$ expression after the sorting procedure.

\section{Transwell migration assay}

Cells were harvested, disaggregated, and resuspended in DMEM$\mathrm{FI} 2$ with $0.2 \% \mathrm{FBS}$ and $5 \times 10^{4}$ cells were seeded in 24-well cell culture inserts with $8 \mu \mathrm{m}$ pore size membrane (Boyden chambers, BD Biosciences). DMEM-FI 2 supplemented with $10 \%$ FBS was added to the lower chamber as chemo-attractant. BK channel blockers, either paxilline or iberiotoxin, were added to DMEMFI 2 at a concentration of 2 or $100 \mathrm{nM}$, respectively, and applied in both the upper and lower part of the chamber. Cells were incubated at $37^{\circ} \mathrm{C}$ for $18 \mathrm{~h}$. After this time, cells were fixed with 
A

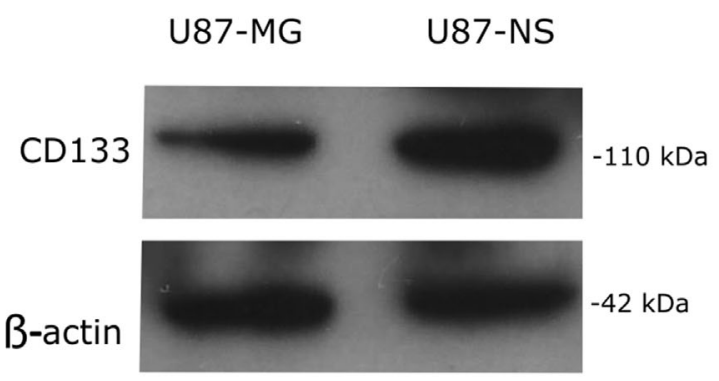

D

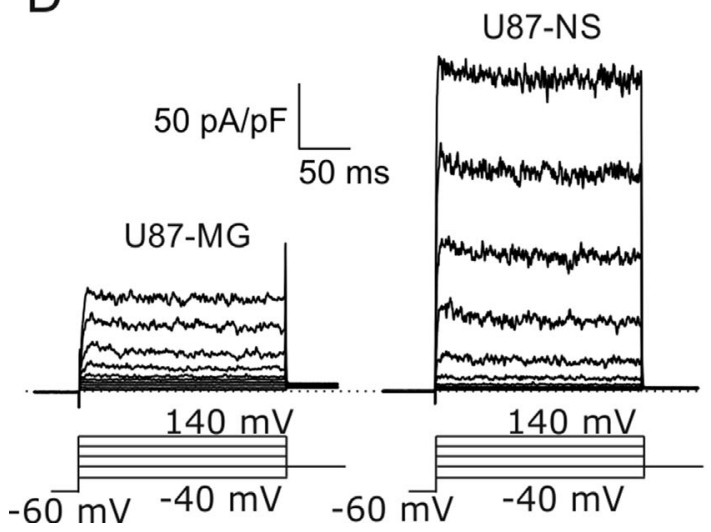

B
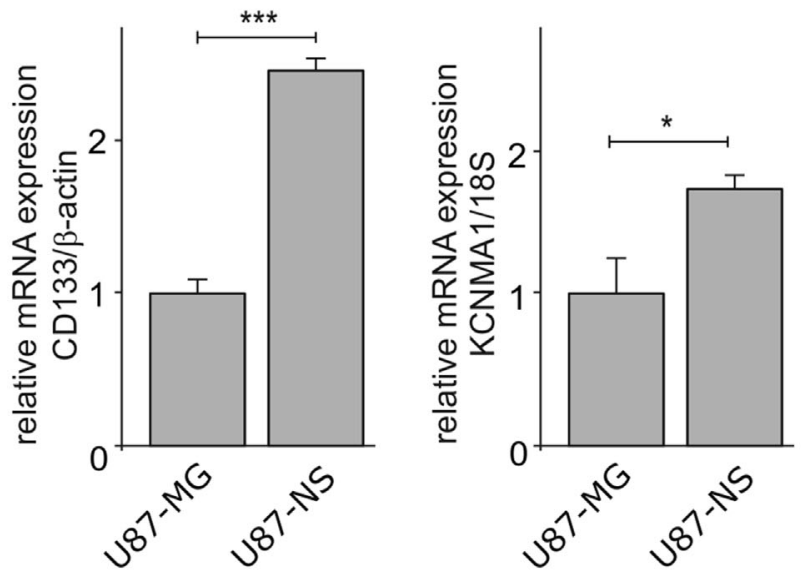

E

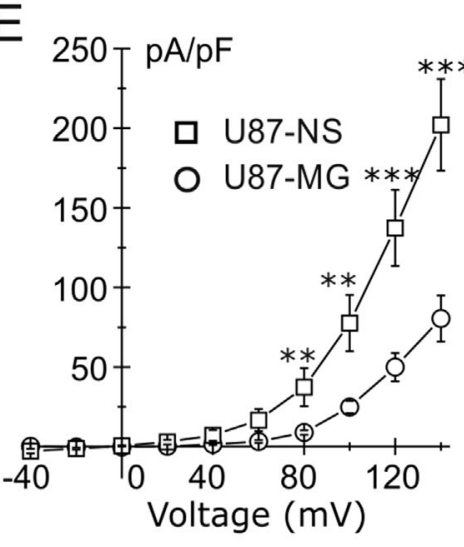

F

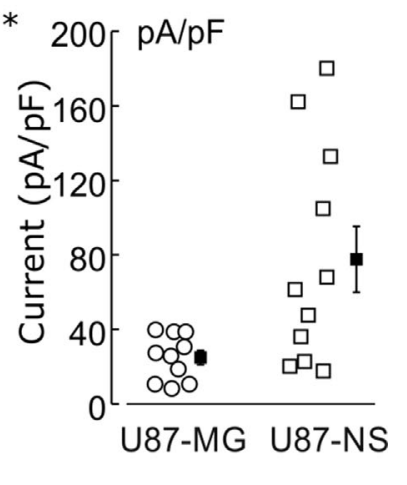

Fig. 2. Up-regulation of BK channels in U87-NS cells. (A and B) Western blot analysis showing the overexpression of CDI33 protein in U87NS compared to U87-MG. (C) Enhanced expression of the mRNA for the BK channel $\alpha$ subunit, assessed by RT-PCR, in U87-NS as compared to U87-MG. ${ }^{*} P<0.05$. (D) Current traces obtained in response to depolarizing steps from -40 to $+140 \mathrm{mV}$ from a holding potential of $-60 \mathrm{mV}$ from a U87-MG cell (left) and a BK-rich U87-NS cell (right). (E) Mean BK I-V assessed from U87-MG (n=I0) and U87-NS (n = II) cells. (F) Dot plot showing the cell-to-cell variability of the BK current density at $+100 \mathrm{mV}$, recorded in U87-MG and U87-NS cells.

$100 \%$ methanol and non migrated cells were removed from the inner side of the insert with a cotton swab. Migrated cells, which had the ability to push themselves through the $8 \mu \mathrm{m}$ pores, were gently rinsed with PBS, stained with $0.25 \%$ crystal violet

(Sigma-Aldrich) for $15 \mathrm{~min}$, rinsed again and allowed to dry. Five random fields per insert were photographed with a light microscope (Leica DM 4000B) at 10× magnification and ImageJ software was used to count cells. In all experiments, data were collected from three chambers.

\section{Immunohistochemistry}

Paraffin-embedded tissues were deparaffinized, rehydrated in descending graded alcohols, incubated for $15 \mathrm{~min}$ in methanol containing $3 \% \mathrm{H}_{2} \mathrm{O}_{2}$ to block endogenous peroxidase activity, and then subjected to microwave antigen retrieval for $20 \mathrm{~min}$ in sodium citrate buffer $(10 \mathrm{mM}$ tri-sodium citrate dihydrate, $0.05 \%$ Tween $20, \mathrm{pH}$ 6.0). After preincubation in normal horse serum for I h, sections were incubated overnight with rabbit polyclonal antiCDI33 antibody (dilution 1:200, abcam 19898) or rabbit polyclonal anti-BK antibody (dilution I:200, APC-I5I, Alomone
Labs) at $4^{\circ} \mathrm{C}$ in humid chamber, washed with PBS, incubated for I $\mathrm{h}$ at room temperature with biotinylated universal secondary antibody (Vectastain Universal Elite ABC kit, Vector Laboratories, Burlingame, CA), washed with PBS and then incubated with the avidin-biotin-peroxidase complex according to the manufacturer's instructions. The sections were then stained with 3-3diaminobenzidine (ImmPACT DAB peroxidase substrate, Vector Laboratories) as chromogen to visualize the reaction product, and were finally counterstained with hematoxylin.

\section{Differentiation assay}

U87 neurospheres at day 14 were trypsinized and disaggregated in order to have a single cell suspension. $4 \times 10^{4}$ cells were plated in $60 \mathrm{~mm}$ tissue culture petri dishes in DMEM supplemented with $10 \%$ FBS in presence or absence of $10 \mu \mathrm{M}$ paxilline and allowed to differentiate for 5 days. Total RNA was extracted and RT-PCR was performed to evaluate mRNA expression of the differentiation marker GFAP and the stemness markers oct-4, sox-2, and nanog. For immunofluorescence, $5 \times 10^{3}$ cells were plated on chamber slides (Nunc Lab-Tek), fixed with $4 \%$ paraformaldehyde, 
permeabilized with $0.5 \%$ PBS-triton $\mathrm{X}-100$, blocked I $\mathrm{h}$ with $0.2 \%$ PBS-gelatin and stained overnight at $4^{\circ} \mathrm{C}$ with the following primary antibodies: rabbit polyclonal anti-GFAP (dilution I:300, Sigma-Aldrich), mouse monoclonal anti-nestin (dilution $1: 300$, Santa-Cruz, Dallas, TX) and mouse monoclonal anti- $\beta$-III tubulin (dilution I:300, Sigma-Aldrich). Secondary antibodies used were: goat anti-mouse Alexa-fluor 594 conjugate and goat anti-rabbit Alexa-fluor 488 (dilution I: 1000, Life Technologies). Nuclei were counterstained with DAPI for $5 \mathrm{~min}$ in the dark and mowiol was used to mount coverslips on chamber slides. Images were acquired with Nikon Eclipse Ni motorized microscope system at $10 \times$ magnification.

\section{Statistical analysis}

All statistical analyses were performed using the Origin v.8 software. A $P$-value $<0.05$ was considered statistically significant.

Results

\section{Expression of BK channel $\alpha$ and $\beta$ subunits in U87-MG GBM cells}

We recorded BK currents from U87-MG GBM cells using the whole-cell configuration of the patch-clamp method, and ionic conditions suitable to isolate this current from others known to be expressed in these cells (cf. Methods). Application of depolarizing steps under these conditions elicited a timedependent outward current associated with a high noise, typical of currents passing through the high-conductance BK channels (Fig. IA). This current was mostly blocked by relatively low concentrations of TEA $(3 \mathrm{mM})$ and paxilline $(2 \mu \mathrm{M})$, and enhanced by the BK channel activator NS 1619 $(20 \mu \mathrm{M})$ (Fig. IA and B). These pharmacological properties indicate that under our conditions we are recording essentially isolated BK currents. In accordance with the

electrophysiological data, RT-PCR analysis detected abundant expression of the KCNMAI transcript coding for the BK channel $\alpha$ subunit (Fig. IC), and, among the BK channel $B$ subunits, only the $\beta 4$ isoform was significantly present in U87MG cells (Fig. IC).

It is known that the association of the $\beta 4$ subunit to the $B K \alpha$ subunit, besides other effects, gives rise to BK currents with highly reduced sensitivity to the toxin blockers charybdotoxin and iberiotoxin (lbTx), while maintaining the original sensitivity to paxilline (Meera et al., 2000; Brenner et al., 2005). We therefore, tested the sensitivity of the BK current expressed in U87-MG cells to $100 \mathrm{nM} \mathrm{IbTx}$ and $2 \mu \mathrm{M}$ paxilline in order to assess the degree to which the $\alpha$ subunit alone and the $\alpha / \beta 4$ subunit complexes contribute to the overall macroscopic BK current. As shown in Figure ID and E, most of the paxillinesensitive current was also lbTx sensitive, suggesting that in U87-MG cells most functional plasma membrane BK channels do not contain $\beta 4$ subunits. These data suggest that $\beta 4$ subunits may contribute to form BK channels in membrane compartments other than the plamamembrane, such as mitochondria (Bednarczyk et al., 2013).

\section{Expression of BK channels in U87-NS versus U87-MG cells}

Cell cultures enriched in stemness markers were obtained by culturing U87-MG cells in stem cell permissive medium

(Ruggieri et al., 2012). Effective cell conditioning was assessed by verifying with optical microscopy and cytofluorimetry, for up to 3 weeks, the appearance of neurospheres and increased fraction of $\mathrm{CDI} 33^{+}$cells (FACS analysis indicated a mean percentage of $\mathrm{CDI} 33^{+}$cells of $49 \pm 4 \%$ in U87-NS cells). After 10 days of conditioning, U87-MG-derived neurospheres (U87NS) showed an evident increase in CDI33 protein expression (Fig. 2A and B). Consistent with the increased expression of
CDI33, in U87-NS cell culture we found a marked inhibition of the differentiation marker GFAP, and a marked upregulation of the cancer stem cell markers, sox-2, nanog, and oct-4, as compared to U87-MG cells, confirming the acquisition of stemlike properties by these cells (data not shown; Ruggieri et al., 20I2).

We next assessed whether U87-NS cells displayed increased BK currents as compared to U87-MG cells. As shown in Figure 2E and $\mathrm{F}$ the mean BK current density in U87-NS cells was about threefold higher than in U87-MG cells, suggesting a differential expression of the BK channel in the two cell types. In accordance, the expression of the KCNMAI transcripts in U87NS cells was almost twofold higher than in control cells not subject to stem cell permissive medium (Fig. 2C). As shown in the dot plot of Figure 2F, the BK current density of U87-NS cells displayed a variability much higher than that observed in U87-MG cells. More specifically, in U87-NS about two thirds of the cells had a BK current density comparable to that observed in U87-MG cells (BK-basal), while the others had BK current densities markedly higher than U87-MG cells, and were called BK-rich cells. Representative current traces from a U87-MG cell and from a BKrich U87-NS cell, activated by depolarizing pulses as indicated, are shown in Figure 2D.

\section{U87-NS stem-like cells express increased plasmamembrane BK channel levels}

As in U87-NS cells mean BK currents and mRNA levels were higher than in U87-MG cells, we hypothesized that high BK channel expression associates with stem-like properties. To verify this assumption, we assessed by cytometric analysis the expression of both BK channels and the stemness marker CDI33 (Fig. 3). U87-MG cells showed a homogeneous morphology and a weak, uniform positivity for the plasmamembrane BK channel (Fig. $3 A-a_{3}$ ), whereas they did not express CDI33 (Fig. 3A-a 4 ). Cell conditioning to neurospheres induced a clear change in cell morphology with the appearance of two distinct subpopulations (cf. Fig. $3 \mathrm{~A}-\mathrm{a}_{\text {I }}$ with B-b $)$ : the first (black population in Fig. 3B-b

characterized by a lower FSC and a higher SSC (e.g., smaller size and higher internal complexity), and the second (light gray population in Fig. 3B- $b_{1}$ ) characterized by a higher FSC and a lower SSC. In the first U87-NS subpopulation, about $21 \%$ of cells had high/very high expression of plasmamembrane BK channel (BK-rich, Fig. 3B-b 3 ) congruent with data shown in Figure $2 \mathrm{~F}$, whereas $70 \%$ of cells were $\mathrm{CDI} 33^{+}$(Fig. 3B-b ${ }_{4}$ ). Furthermore, $25 \%$ of the cells in this subpopulation co-expressed both markers (dot plot in Fig. 3B-b $b_{2}$ ), which would imply that virtually all BK-rich cells are positive to CDI33. Conversely, the second subpopulation was essentially negative for both markers (Fig. 3B-b $b_{5-7}$ ). These results show the presence, in U87-NS cells, of a BK-rich subpopulation highly expressing the CDI33 marker.

The BK-rich subpopulation expresses high levels of other stemness markers

We have shown that virtually all BK-rich U87-NS cells (ca 20\%) co-express CDI33, making the BK channel a potential stemness marker. To verify this proposition, in both the BKrich and BK-basal subpopulations we assessed the expression of other stemness markers. To this purpose, we isolated BKrich and BK-basal subpopulations by cell sorting (Fig. 4, upper panels), and on each subpopulation we assessed the expression of several stemness markers by RT-PCR. As shown in Figure 4, lower panel, BK-rich cells also expressed markedly higher mRNA levels for oct-4, sox-2, and nanog, as compared to 


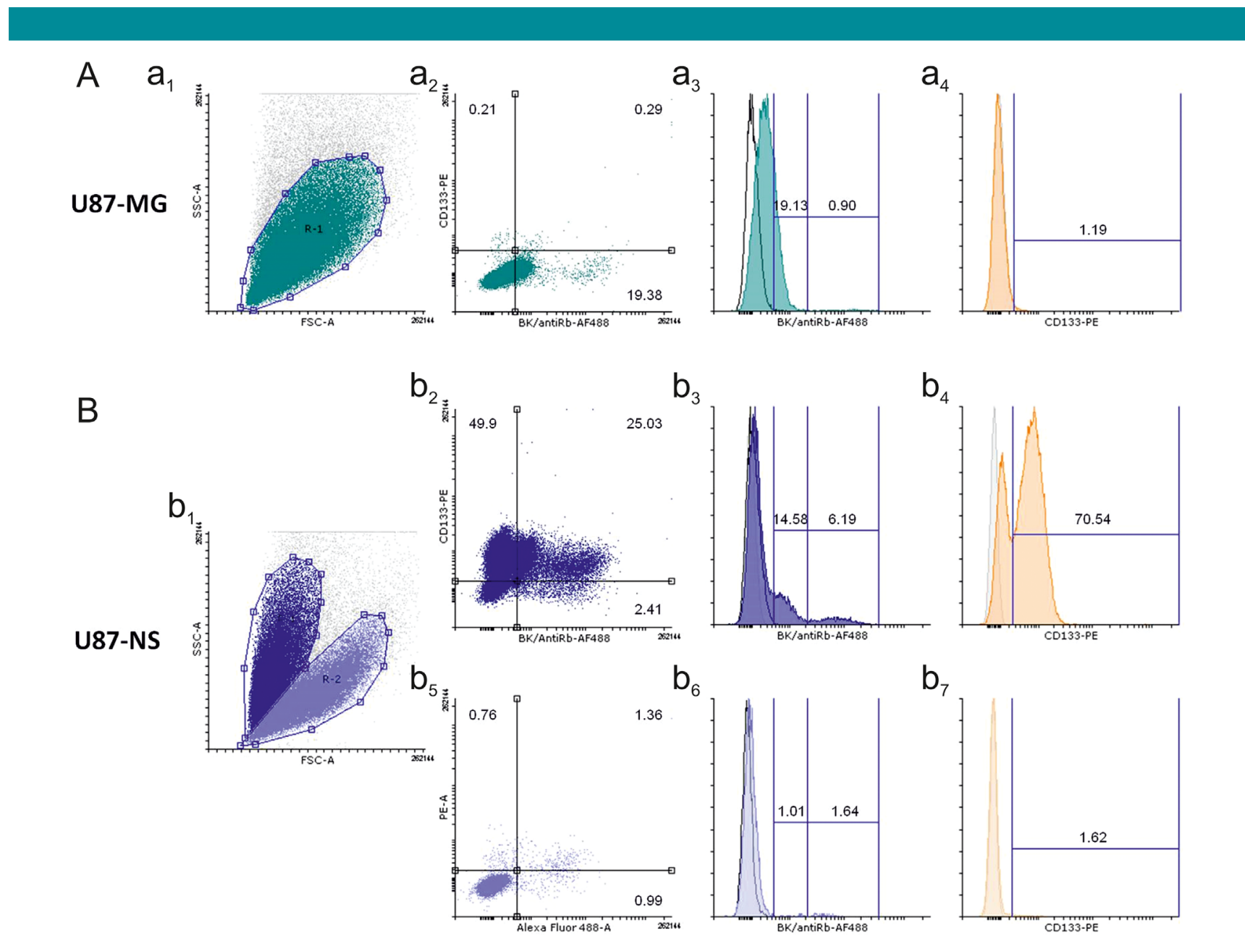

Fig. 3. Expression of CDI33 in the BK-rich subpopulation of U87-NS cells. Cytometric analysis of U87-MG (A) and U87-NS (B) cells. FSC/SSC cytograms show a uniform cell population for U87-MG $\left(a_{1}\right)$ and the appearance of two cellular subsets for U87-NS $\left(b_{1}\right)$. BK/CDI33 coexpression is shown for U87-MG $\left(a_{2}\right)$ and for the two cellular subsets of U87-NS $\left(b_{2}\right.$ and $b_{5}$, respectively). Histogram plots show BK and CDI 33 expression in U87-MG $\left(a_{3}\right.$ and $\left.a_{4}\right)$ and in the two cellular subsets of U87-NS $\left(b_{3}, b_{4}, b_{6}\right.$, and $\left.b_{7}\right)$. One out of three independent experiments is shown.

BK-basal cells. The strong segregation of BK channels with several stemness markers makes these channels potential candidates as marker for GBM stem cells.

\section{Correlation between stem cell markers and BK channel expression in primary cell lines}

To verify whether the significant co-expression found between stem cell markers and BK channels also occurred in primary GBM cell lines, we estimated the mRNA levels of the stemness marker CDI33 and the BK channel $\alpha$ subunit in five primary cell lines obtained from freshly resected biopsies. As shown in Figure 5A, a highly significant correlation was found between KCNMAI and CDI 33 mRNA levels, with a Pearson coefficient of $0.98(P<0.002)$. For one of the tested lowpassage primary cultures (FCN), we were able to record the BK currents using the patch-clamp method. As found in established GBM cell lines, FCN cells expressed mostly lbTxsensitive $B K$ currents in response to depolarizing steps (Fig. 5B). In contrast to both the U87-MG and the U87-NS cell lines, the $B K$ current expressed in these primary cells showed an evident inactivation and a more hyperpolarized steady-state activation threshold, suggesting the contribution of $B$ subunits in determining these channel properties. In accordance, using RT-PCR we found that this GBM primary culture, in contrast to both the U87-NS and U87-MG cells, expressed abundant levels of the 32 subunit (Fig. 5D). From this cell line we were able, upon cell conditioning with stem cell permissive medium, to obtain neurospheres (FCN-NS) from which we recorded BK currents. Notably, also FCN-NS cells possessed a BK current sensibly higher than that recorded in FCN cells (Fig. 5C and E). Finally, in a freshly resected biopsy, from patient STCI, we used immunohistochemistry to look at the $\mathrm{BK}$ and $\mathrm{CD} / 33$ protein expression (Fig. 5F). As shown, the BK channel is present in all tumor areas examined, including perivascular sites, with a percentage of clearly BK positive cells varying approximately between $10 \%$ and $30 \%$. The majority of neoplastic multinucleated cells were instead negative or weakly positive for BK. The expression of CDI33 is similar in tissue distribution but differs in the percentage of positive cells, which varies between $30 \%$ and $40 \%$. We also extracted from the same tissue the total RNA and found higher KCNMAI and CDI 33, and lower GFAP mRNA expression as compared to that observed in biopsies from normal (non-tumoral) tissue (Fig. 5G). 
A
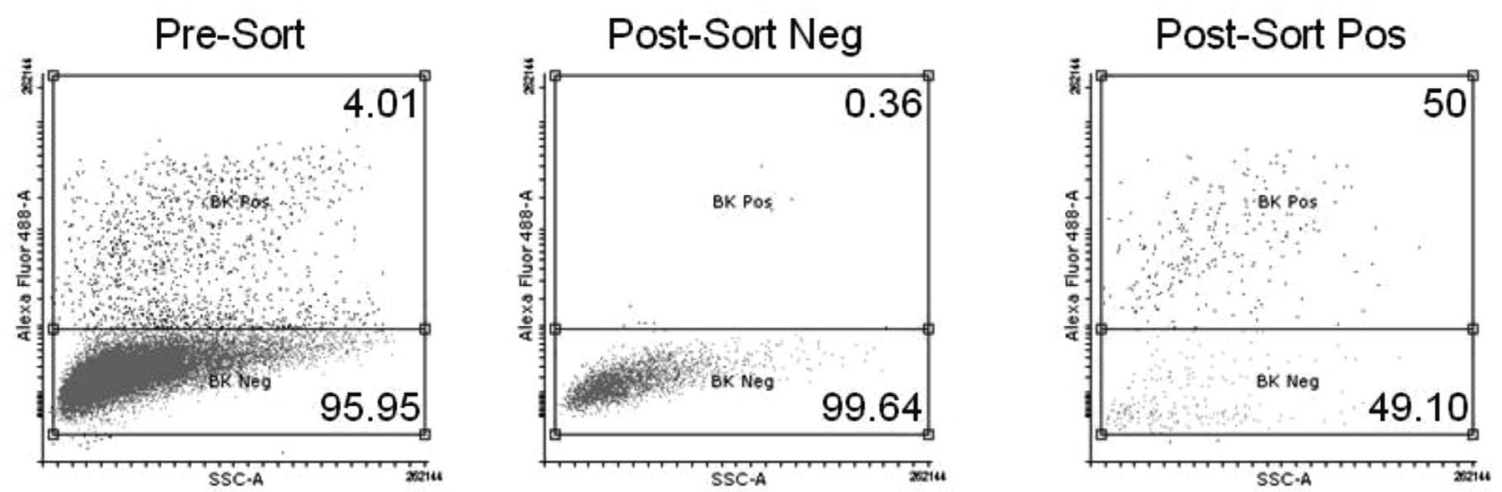

B

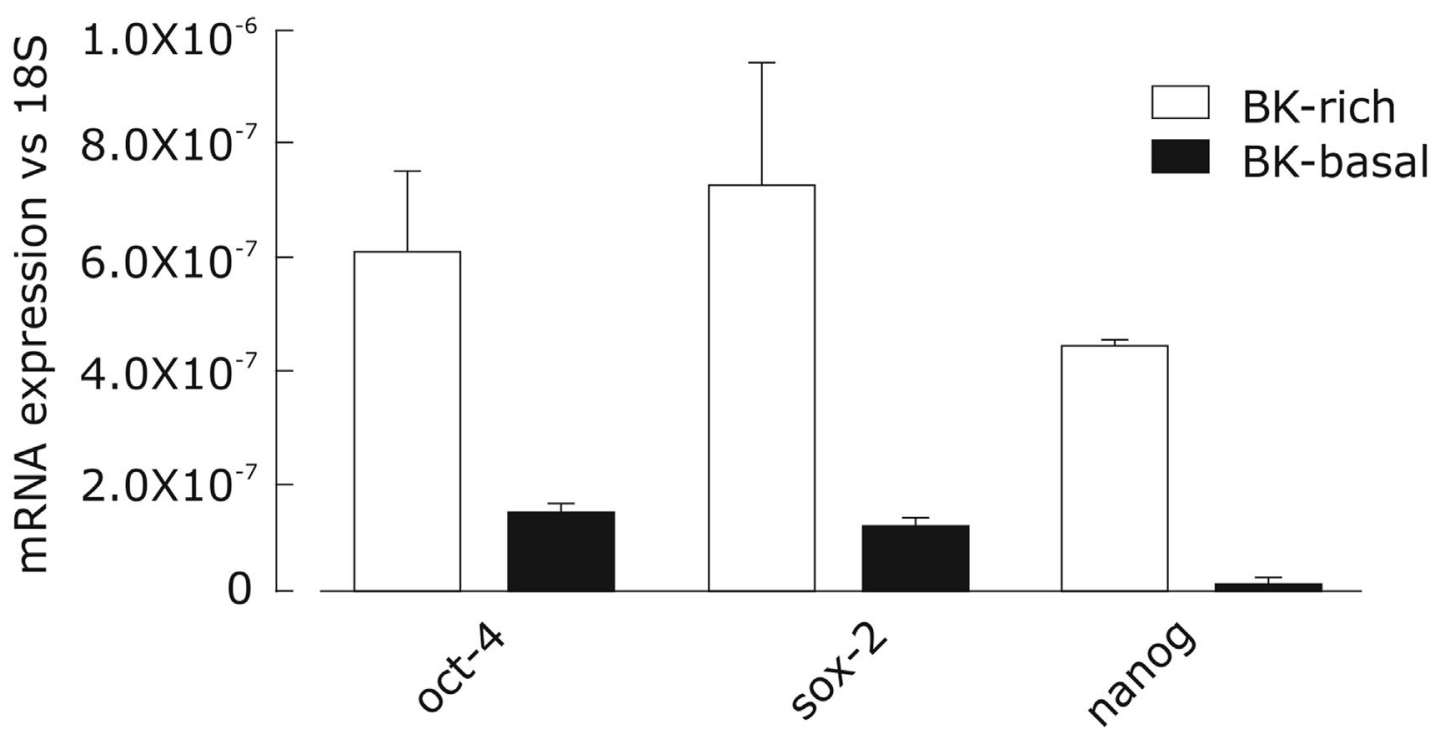

Fig. 4. Expression of stemness markers other that CDI33 in the BK-rich U87-NS cells. (A) FACS cell sorting of BK-rich and BK-basal cells from U87-NS. (B) RT-PCR analysis showing mRNA expression of the stemness markers oct-4, sox-2, and nanog in BK-rich and BK-basal cells.

\section{Role of the BK channel in the migration of U87-MG and} U87-NS cells

Given the large plasmamembrane expression of BK channels in U87-NS cells and their recognized role in cell volume regulation, we looked for the contribution of these channels to the migration of these cells. To this end, we performed transwell migration assays and looked at the effects of BK channel specific inhibition. As shown in Figure 6, paxilline ( $\mathrm{Pax}$ ) had a small effect on U87-MG cell migration, but a strong inhibitory effect (about $60 \%$ inhibition) on the migration of U87-NS cells, suggesting that the overexpression of BK channels in U87-NS cells is functionally relevant to promote their migration. Since paxilline is membrane permeant, its effect on cell migration may be also ascribed to block of mithocondrial BK channels, much expressed in U87-MG cells (Siemen et al., 1999; Bednarczyk et al., 2013). In order to exclude this possibility, we tested the effects of the membraneimpermeant lbTx on GBM cell migration. As shown in Figure 6,
lbTx displayed effects in line with those observed using paxilline, suggesting that plasmamembrane BK channels are those relevant for the migration of U87-NS cells.

\section{Role of the BK channel in the differentiation of U87-NS cells}

Finally, we performed differentiation assays by using 10\% FBS as inductor of differentiation, and looked at neuronal $(\beta-$-III tubulin), astrocyte (GFAP), and stemness (nestin, oct-4, nanog, and sox-2) markers by RT-PCR and immunofluorescence. In addition, we repeated the differentiation assays in presence of the BK channel blocker paxilline to check the role of BK channel activity in the differentiation of U87-NS cells. As shown by the immunofluorescence in Figure 7, U87-NS cells expressed low levels of both GFAP and $\beta$-III tubulin (Fig. 7B), and high levels of nestin (Fig. 7C). In addition, oct-4, nanog, and sox-2 trancripts were upregulated (Fig. 7A), confirming the 
A

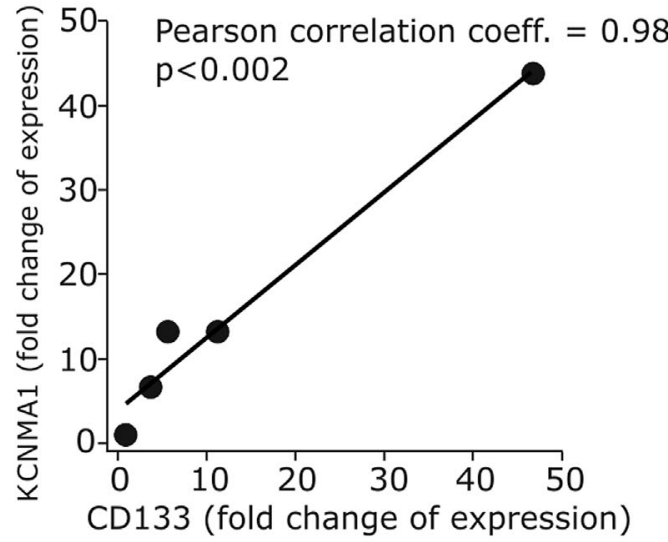

D

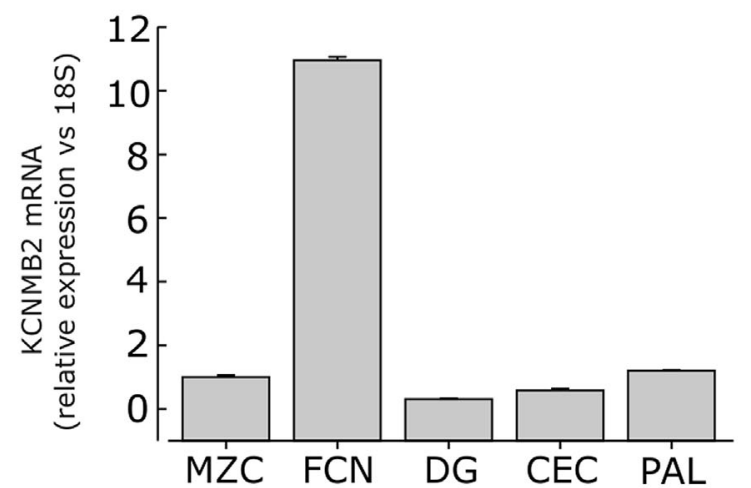

F

\section{anti-BK}

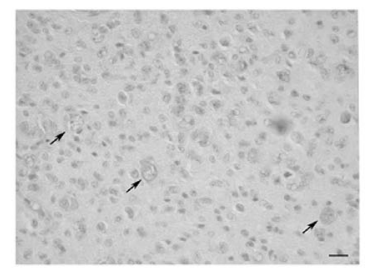

B
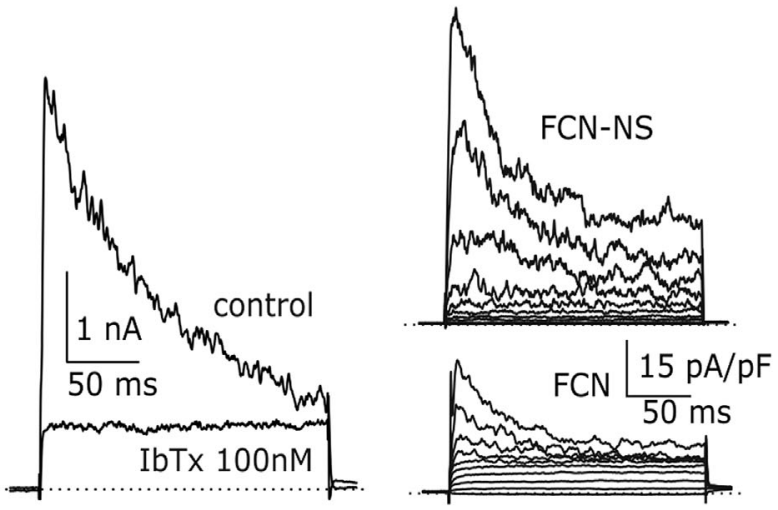

$\mathrm{E}$

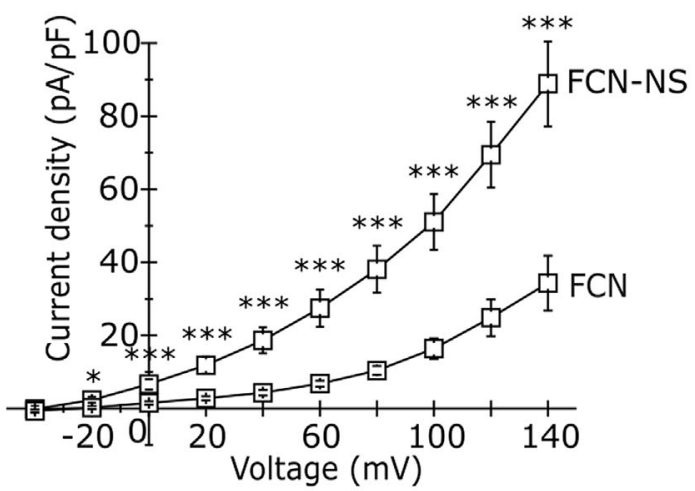

G

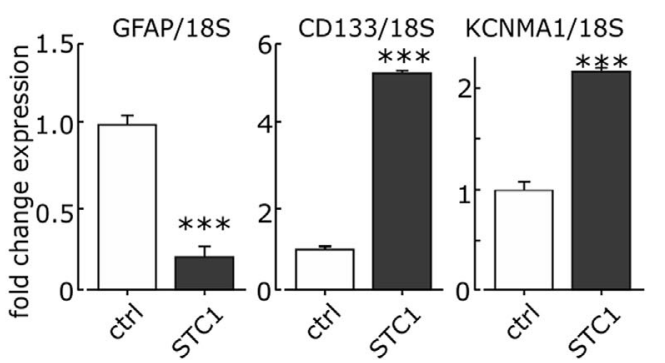

Fig. 5. Correlation between CDI33 and BK channel expression in GBM primary cell lines. (A) Correlation plot between CDI33 and KCNMAI mRNA levels from five primary cells lines obtained from freshly resected GBM biopsies. (B) Current traces in response to a depolarizing pulse to $+100 \mathrm{mV}$, in control and in presence of $100 \mathrm{nM} \mathrm{lbTx}$, for a FCN primary GBM cell. (C) Current traces obtained in response to depolarizing steps from -40 to $+140 \mathrm{mV}$ from a holding potential of $-60 \mathrm{mV}$ from a FCN cell (left) and a FCN-NS cell (right). (E) Mean BK I-V assessed from FCN $(n=9)$ and FCN-NS $(n=9)$ cells. (D) B2 subunit transcript level in the same five primary cells lines, assessed by RT-PCR. (F) Serial paraffin sections of fresh bioptic GBM tissue from STCI patient were tested for BK and CDI33 by immunohistochemistry. Scale bar: $20 \mu \mathrm{m}$. (G) Fresh tissue from the same STCI tumor was processed for mRNA extraction and analyzed by RT-PCR for KCNMAI, CDI33, and GFAP genes. Normal (non-tumoral) brain tissue from same patient was used as control (ctrl). ${ }_{* * *} \boldsymbol{P}<0.00 \mathrm{I}$.

stemness properties of these cells. Treatment with 10\% FBS substantially increased both differentiation markers, and decreased stemness markers, confirming the differentiation ability of this maneuver. Notably, in presence of paxilline the FBS-induced upregulation of GFAP was markedly strengthened, while the induction of $\beta$-III tubulin appeared to be partially prevented. In addition, paxilline enhanced the FBS-induced downregulation of oct-4 and nanog (Fig. 7A). These results suggest that the presence and activity of BK channels enhance the stemness properties of U87-NS cells and preclude their differentiation toward the astrocyte lineage, while favoring the differentiation toward the neuronal lineage. 


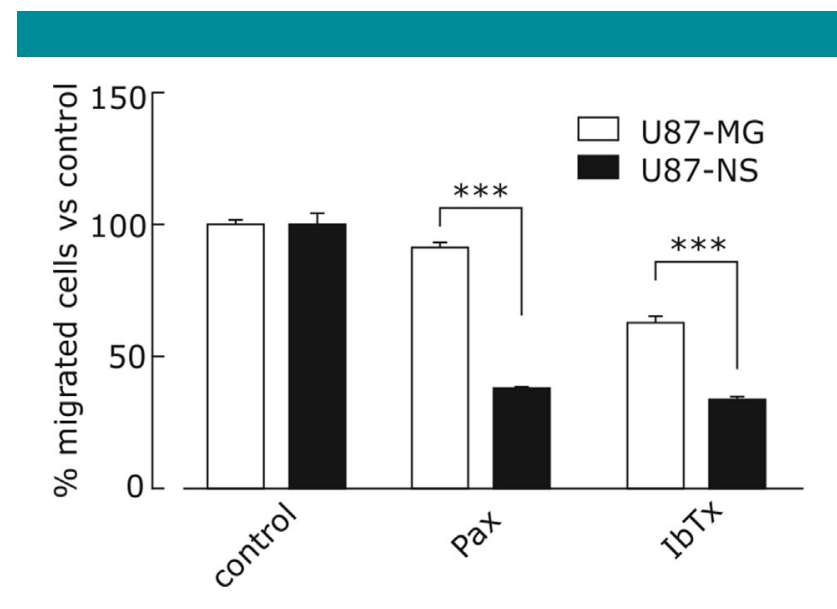

Fig. 6. Effects of BK channel inhibition on the transwell migration of U87-MG and U87-NS cells. Plot showing the percentage of migrated U87-MG (white) and U87-NS (black) cells, tested under control condition, in presence of $2 \mu \mathrm{M}$ Pax, or in presence of $100 \mathrm{nM}$ IbTx. A markedly different inhibition by Pax and lbTx was observed in the two different cell types $\left({ }^{* * *} P<0.001\right)$.

\section{Discussion}

The main findings reported in this work are that: (i) U87-MG cells grown under conditions that enriched the culture in GBM stem-like cells (U87-NS) express higher levels of BK channels as compared to normally grown cells; (ii) the BK channel's increased expression in U87-NS cultures is due to the enrichment of a BK-rich subpopulation expressing stem cell markers; (iii) unlike U87-MG, U87-NS cell migration is strongly sustained by the activity of BK channels. All these data indicate that BK channels are highly expressed in GBM stem-like cells, where they participate to their high migratory ability.

We found that U87-MG cells express a relatively high density of BK currents that, at the low $\left[\mathrm{Ca}^{2+}\right]_{i}$ used in our recording solutions, activate at membrane depolarizations higher than $+60 \mathrm{mV}$. In this respect, the BK current of U87MG cells resembles those found in other GBM cell lines and in GBM primary cultures isolated from freshly resected biopsies (Ransom et al., 2002; Weaver et al., 2006; Fioretti et al., 2009; Wondergem and Bartley, 2009; Abdullaev et al., 20I0; McFerrin et al., 20I2). At the transcript level, we found that U87-MG cells express both the mRNA coding for the $\alpha$ and the $B 4$ subunits. However, the high sensitivity of BK channels to relatively low concentrations of IbTx suggests that the $B 4$ subunit, while if expressed at protein level, does not participate to form plasmamembrane functional BK channels. Notably, in some neuronal cell types it has been found that $\$ 4$ subunits do not significantly reach the plasmamembrane, but are retained in the endoplasmic reticulum where they modulate negatively the plasmamembrane targeting of the BK $\alpha$ subunits (Shruti et al., 2012). Alternatively, $B 4$ subunits may participate to form functional BK channels in subcellular compartments other than the plasmamembrane. Interestingly, recent works suggest a significant expression of $\$ 4$ subunits at the mitochondrial membrane of GBM cells, where ion channels with typical BK channels properties have been often identified (Siemen et al., 1999; Bednarczyk et al., 2013; Gu et al., 20l4).

A main finding of this study is that GBM stem-like cells express BK channels at a much higher density than non-stem-like cells. More specifically, we found that U87-MG cells conditioned with growth factors that enrich the culture in cells expressing stem cell markers (U87-NS cells) express a mean BK current density significantly higher than U87-MG cells grown in serum-containing medium. Consistent with these data, the mRNA levels for the BK $\alpha$ subunit in U87-NS cells were markedly higher as compared to U87-MG cells. FACS analysis showed that U87-NS cells expressing high levels of plasmamembrane BK channels also expressed relatively high levels of the stem cell marker CDI33. Interestingly, a strong correlation between the level of the BK channel $\alpha$ subunit transcripts and the CDI33 transcripts was also found in primary GBM cultures derived from freshly resected biopsies. This result suggests that the overexpression of BK channels in CDI33-positive, stem-like GBM cells is not a specific feature of U87 cells, but a general feature of GBM. Several studies have reported a high BK channel expression in cells with stem-like properties. A relatively high density of BK channels was found in mouse and human embryonic stem cells (Soria et al., 20l3), and in mesenchymal stem cells derived from both human-induced pluripotent stem cells and bone marrow (Zhang et al., 20I2). The expression level of BK channels in oligodendroglial precursor cells was found to decrease with developmental age (Buttigieg et al., 20II). Finally, as found in several GBM cell types, BK channels were found significantly more expressed in the CDI33-positive subpopulation of neuroblastoma SH-SY5Y cells as compared to the CDI33negative subpopulation (Park et al., 2010). All these evidences suggest that the high expression of BK channels is a general feature of cells with stem-like properties. We are aware that GBM cancer stem cells represent a heterogeneous population, and that CDI33 may not be expressed in some subgroups of stem-like cells (Beier and Beier, 20I I). Nevertheless, we selected CDI33 as stemness marker given the wide literature demonstrating its role in tumorigenesis and in the maintenance of the stemness properties (Choy et al., 2012; Brescia et al., 2013).

A number of works have shown that GBM stem-like cells have a strong invasive potential, and this property contributes to the increased aggressiveness of this cell subpopulation as compared to non-stem like cells (Yu and Bian, 2009; Inoue et al., 2010; Wu et al., 20I I; Chen et al., 20I3). BK channel activity has been shown essential for GBM cell migration, especially when cells infiltrate through the narrow extracellular space typical of the healthy brain parenchyma, that likely requires significant volume changes (Soroceanu et al., 1999; Weaver et al., 2006). Based on these evidences, we hypothesized that the increased expression of BK channels in GBM stem-like cells may be instrumental to their increased migratory ability. In accordance, we found that the BK channel inhibitor paxilline was highly effective in contrasting migration of U87-NS as compared to U87-MG cells. The effect of BK channel silencing on the migration of U87-MG was also demonstrated by Edalat et al. (2016). Our results are in accordance with a prominent role of BK channels in establishing the migratory activity of stem-like GBM cells, and suggest that the inhibition of these channels may represent a potential strategy to reduce the aggressiveness of this important GBM cell subpopulation.

We finally found that BK channels may have a significant role in maintaining the stemness properties of GBM stem-like cells. Using a differentiation assay based on the induction of differentiation by FBS, we indeed found that block of BK channel by paxilline substantially interfered with the differentiation of U87-NS cells, in a way to suggest that the activity of BK channels in U87-NS cells precludes the differentiation toward the astrocyte lineage, while favoring the 
A
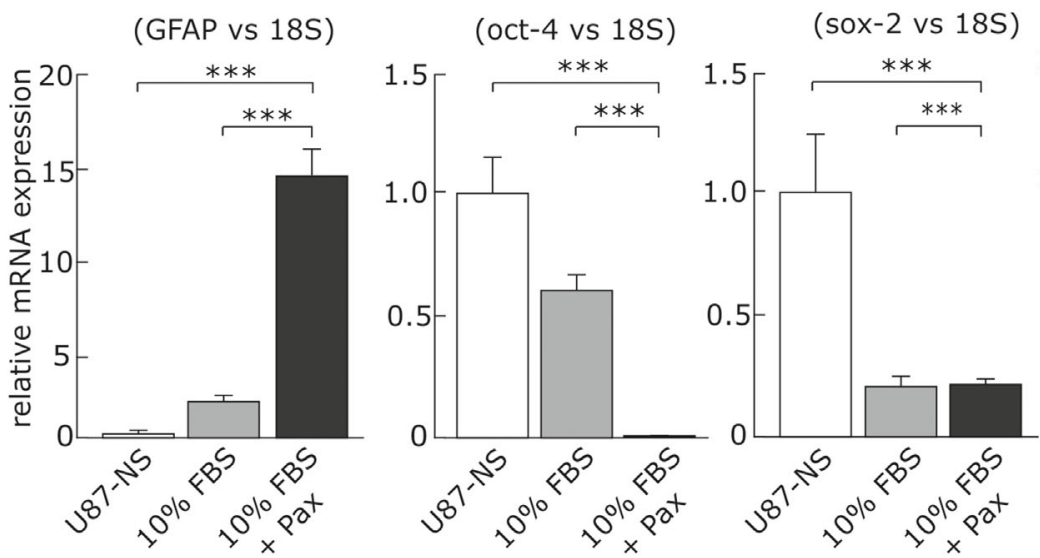

(nanog vs 18S)

B

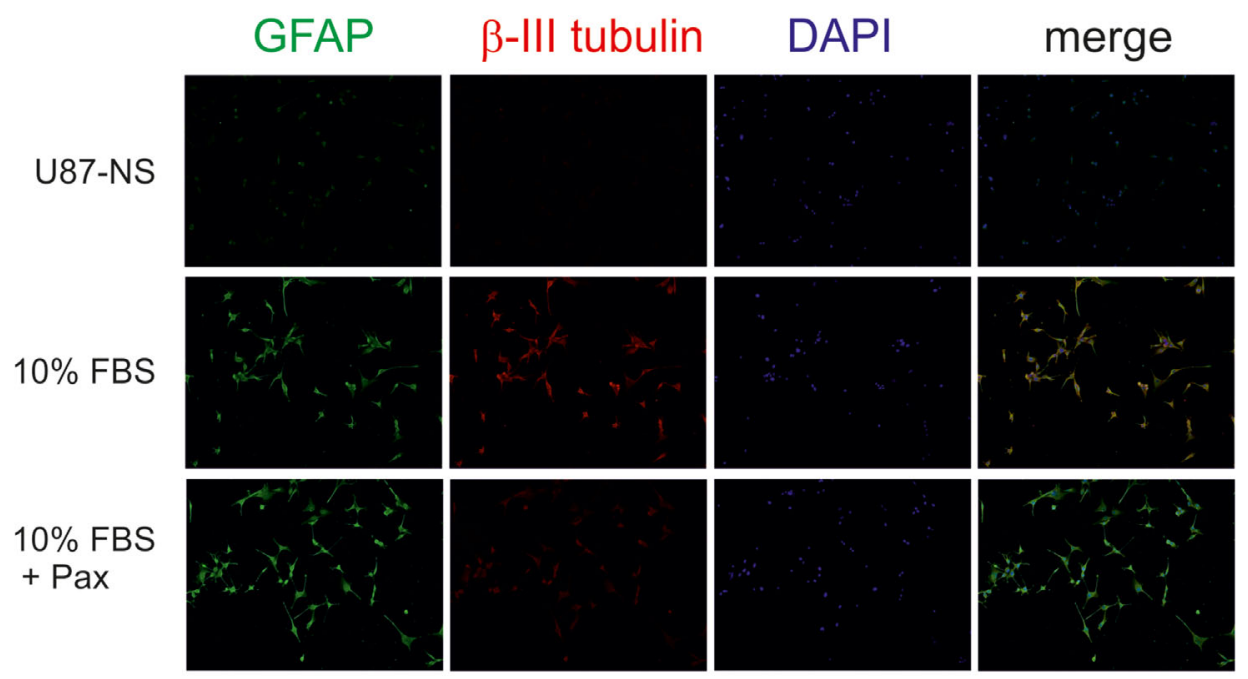

C

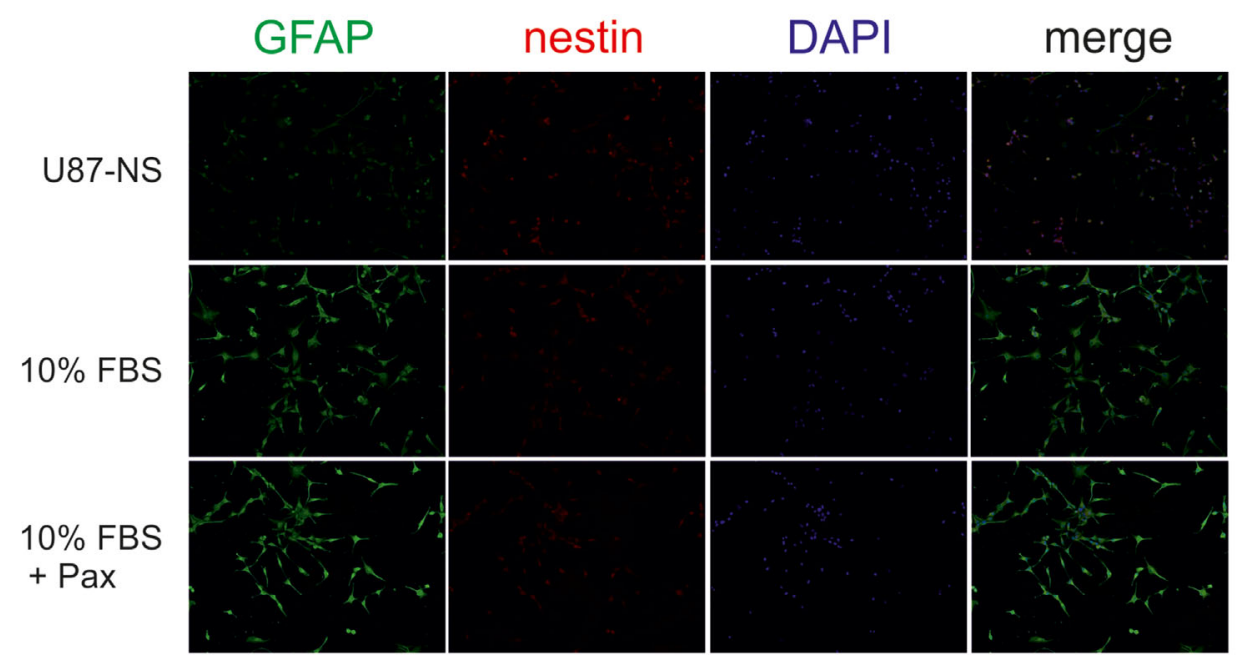

Fig. 7. Effects of BK channel inhibition on differentiation of U87-NS. (A) RT-PCR analysis showing mRNA expression of GFAP and the stemness markers oct-4, SOX-2, and nanog in differentiated U87-NS (cultured for 5 days with $10 \%$ FBS) in presence or absence of $10 \mu M$ Pax compared to undifferentiated U87-NS cells ( ${ }^{* *} \boldsymbol{P}<0.01 ;{ }^{* * *} \boldsymbol{P}<0.001$ ). (B and C) Co-expression of GFAP (green)/ $\beta$-III tubulin (red) (B) and GFAP (green)/nestin (red) (C) in U87-NS cells differentiated for 5 days with $10 \%$ FBS in presence or absence of Pax. Magnification I0 $\times$. 
differentiation toward the neuronal lineage. Block of BK channels also resulted in a stronger differentiation ability of U87-NS cells. These results suggest that modulation of this channel may be considered in GBM therapies based on tumor cell differentiation.

In conclusion, we have shown that plasmamembrane BK channels are highly expressed in GBM stem-like cells, where they participate to their high migratory ability. These data point to BK channels as a potential therapeutic target for this pathology allowing to identify new molecular characteristics of the GBM regulation network that may increase the precision of personalized medication.

\section{Acknowledgments}

The authors would like to acknowledge the financial support of MIUR-PRIN (20108WT59Y.004), Ministero della Salute (GR2009-I580433), and Fondazione Cassa di Risparmio di Perugia (20I2.0240.02I and 20I4/222I).

\section{Literature Cited}

Abdullaev IF, Rudkouskaya A, Mongin AA, Kuo YH. 20I0. Calcium-activated potassium channels BK and IKI are functionally expressed in human gliomas but do not regulate cell proliferation. PLOS ONE 5:el2304.

Bao S, Wu Q, McLendon RE, Hao Y, Shi Q, Hjelmeland AB, Dewhirst MW, Bigner DD, Rich JN. 2006. Glioma stem cells promote radioresistance by preferential activation of the DNA damage response. Nature 444:756-760.

Bednarczyk P, Wieckowski MR, Broszkiewicz M, Skowronek K, Siemen D, Szewczyk A. 2013. Putative structural and functional coupling of the mitochondrial $B K(C a)$ channel to the respiratory chain. PLOS ONE 8:e68I25.

Beier CP, Beier D. 20II. CDI33 negative cancer stem cells in glioblastoma. Front Biosci (Elite Ed) 3:70I-7I0.

Brenner R, Chen QH, Vilaythong A, Toney GM, Noebels JL, Aldrich RW. 2005. BK channel beta4 subunit reduces dentate gyrus excitability and protects against temporal lobe seizures. Nat Neurosci 8:1752-1759.

Brescia P, Ortensi B, Fornasari L, Levi D, Broggi G, Pelicci G. 2013. CDI33 is essential for glioblastoma stem cell maintenance. Stem Cells 31:857-869.

Buttigieg J, Eftekharpour E, Karimi-Abdolrezaee S, Fehlings MG. 20I I. Molecular and electrophysiological evidence for the expression of BK channels in oligodendroglial precursor cells. Eur J Neurosci 34:538-547.

Calogero A, Arcella A, De Gregorio G, Porcellini A, Mercola D, Liu C, Lombari V, Zani M, Giannini G, Gagliardi FM, Caruso R, Gulino A, Frati L, Ragona G. 200I. The early growth response gene EGR-I behaves as a suppressor gene that is down-regulated independent of ARF/Mdm2 but not $\mathrm{p} 53$ alterations in fresh human gliomas. Clin Cancer Res 7:2788-2796.

Catacuzzeno L, Aiello F, Fioretti B, Sforna L, Castigli E, Ruggieri P, Tata AM, Calogero A, Franciolini F. 20II. Serum-activated $\mathrm{K}$ and $\mathrm{Cl}$ currents underlay U87-MG glioblastoma cell migration. J Cell Physiol 226:1926-1933.

Catacuzzeno L, Michelucci A, Sforna L, Aiello F, Sciaccaluga M, Fioretti B, Castigli E, Franciolini F. 2014. Identification of key signaling molecules involved in the activation of the swelling-activated chloride current in human glioblastoma cells. J Membr Biol the swelling-

Catacuzzeno L, Caramia M, Sforna L, Belia S, Guglielmi L, D'Adamo MC, Pessia M, Franciolini F. 20I5. Reconciling the discrepancies on the involvement of large-conductance $\mathrm{Ca}(2+)$ activatedK channels in glioblastoma cell migration. Front Cell Neurosci 9:152.

Catacuzzeno L, Fioretti B, Franciolini F. 2012. Expression and role of the intermediateconductance calcium-activated potassium channel $\mathrm{KCa} 3 . \mathrm{I}$ in glioblastoma. J Signal Transduct 2012:421564.

Chen X, Chen L, Chen J, Hu W, Gao H, Xie B, Wang X, Yin Z, Li S, Wang X. 2013. ADAMI7 promotes U87 glioblastoma stem cell migration and invasion. Brain Res 1538:151-158. Choy W, Nagasawa DT, Trang A, Thill K, Spasic M, Yang I. 2012. CDI33 as a marker for regulation and potential for targeted therapies in glioblastoma multiforme. Neurosurg Clin N Am 23:391-405.

Cuddapah VA, Sontheimer H. 20I I. Ion channels and transporters [corrected] in cancer. 2. Ion channels and the control of cancer cell migration. Am J Physiol Cell Physiol 301:54I-549.

Eckel-Passow JE, Lachance DH, Molinaro AM, Walsh KM, Decker PA, Sicotte H, Pekmezci M, Rice T, Kosel ML, Smirnov IV, Sarkar G, Caron AA, Kollmeyer TM, Praska CE, Chada AR, Halder C, Hansen HM, McCoy LS, Bracci PM, Marshall R, Zheng S, Reis GF, Pico AR, O'Neill BP, Buckner JC, Giannini C, Huse JT, Perry A, Tihan T, Berger MS, Chang SM, Prados MD, Wiemels J, Wiencke JK, Wrensch MR, Jenkins RB. 2015. Glioma groups based on Ip/I9q, IDH, and TERT promoter mutations in tumors. N Engl J Med 372:2499-2508.

Edalat L, Stegen B, Klumpp L, Haehl E, Schilbach K, Lukowski R, Kühnle M, Bernhardt G, Buschauer A, Zips D, Ruth P, Huber SM. 2016. BK K + channel blockade inhibits radiationinduced migration/brain infiltration of glioblastoma cells. Oncotarget 7:14259-14278.
Eskandari S, Zampighi GA, Leung DW, Wright EM, Loo DD. 2002. Inhibition of gap junction hemichannels by chloride channel blockers. J Membr Biol 185:93-102.

Fioretti B, Castigli E, Micheli MR, Bova R, Sciaccaluga M, Harper A, Franciolini F, Catacuzzeno L. 2006. Expression and modulation of the intermediate- conductance $\mathrm{Ca} 2+$-activated $\mathrm{K}+$ channel in glioblastoma GL-I5 cells. Cell Physiol Biochem 18:47-56.

Fioretti B, Catacuzzeno L, Sforna L, Aiello F, Pagani F, Ragozzino D, Castigli E, Franciolini F. 2009. Histamine hyperpolarizes human glioblastoma cells by activating the intermediateconductance Ca2+-activated K+ channel. Am J Physiol Cell Physiol 297:CI02-CIIO. Gu XQ, Pamenter ME, Siemen D, Sun X, Haddad GG. 2014. Mitochondrial but not plasmalemmal BK channels are hypoxia-sensitive in human glioma. Glia 62:504-513.

Holland EC. 200I. Gliomagenesis: Genetic alterations and mouse models. Nat Rev Genet 2:120-129.

noue A, Takahashi H, Harada H, Kohno S, Ohue S, Kobayashi K, Yano H, Tanaka J, Ohnishi T. 20I0. Cancer stem-like cells of glioblastoma characteristically express MMP-I 3 and display highly invasive activity. Int J Oncol 37:|121-1131.

Kyle BD, Braun AP. 20I4. The regulation of BK channel activity by pre- and post-translational modifications. Front Physiol 5:316.

Liu X, Chang Y, Reinhart PH, Sontheimer H, Chang Y. 2002. Cloning and characterization of glioma BK, a novel BK channel isoform highly expressed in human glioma cells. J Neurosci 22:1840-1849.

Maher EA, Furnari FB, Bachoo RM, Rowitch DH, Louis DN, Cavenee WK, DePinho RA. 200 I. Malignant glioma: Genetics and biology of a grave matter. Genes Dev 15:13 | I-1333.

Maugeri-Saccà M, Di Martino S, De Maria R. 2013. Biological and clinical implications of cancer stem cells in primary brain tumors. Front Oncol 3:6.

Maugeri-Saccà M, Zeuner A, De Maria R. 20II. Therapeutic targeting of cancer stem cells. Front Oncol I:I0.

McFerrin MB, Turner KL, Cuddapah VA, Sontheimer H. 20I2. Differential role of IK and BK potassium channels as mediators of intrinsic and extrinsic apoptotic cell death. Am J Physiol Cell Physiol 303:C1070-Cl078.

Meera P, Wallner M, Toro L. 2000. A neuronal beta subunit (KCNMB4) makes the large conductance, voltage- and $\mathrm{Ca} 2+$-activated $\mathrm{K}+$ channel resistant to charybdotoxin and iberiotoxin. Proc Natl Acad Sci USA 97:5562-5567.

Park JH, Park SJ, Chung MK, Jung KH, Choi MR, Kim Y, Chai YG, Kim SJ, Park KS. 2010. High expression of large-conductance $\mathrm{Ca} 2+$-activated $\mathrm{K}+$ channel in the CDI33+ subpopulation of SH-SY5Y neuroblastoma cells. Biochem Biophys Res Commun 396:637-642.

Ransom CB, Liu X, Sontheimer H. 2002. BK channels in human glioma cells have enhanced calcium sensitivity. Glia 38:28I-291.

Ruggieri P, Mangino G, Fioretti B, Catacuzzeno L, Puca R, Ponti D, Miscusi M, Franciolini F, Ragona G, Calogero A. 2012. The inhibition of KCa3.I channels activity reduces cell motility in glioblastoma derived cancer stem cells. PLoS ONE 7: e47825.

Sforna L, Cenciarini M, Belia S, D'Adamo MC, Pessia M, Franciolini F, Catacuzzeno L. 2015 The role of ion channels in the hypoxia-induced aggressiveness of glioblastoma. Front Cell Neurosci 15:467.

Sforna L, Cenciarini M, Belia S, Michelucci A, Pessia M, Franciolini F, Catacuzzeno L. 2016. Hypoxia modulates the swelling-activated $\mathrm{Cl}$ current in human glioblastoma cells: Role in volume regulation and cell survival. J Cell Physiol In press.

Shruti S, Urban-Ciecko J, Fitzpatrick JA, Brenner R, Bruchez MP. 2012. The brain-specific Beta4 subunit downregulates BK channel cell surface expression. PLoS ONE 7:e33429. Siemen D, Loupatatzis C, Borecky J, Gulbins E, Lang F. 1999. Ca2+-activated K channel of the BK-type in the inner mitochondrial membrane of a human glioma cell line. Biochem Biophys Res Commun 257:549-554.

Sontheimer H. 2008. An unexpected role for ion channels in brain tumor metastasis. Exp Biol Med (Maywood) 233:779-791.

Soria B, Navas S, Hmadcha A, Hamill OP. 2013. Single mechanosensitive and $\mathrm{Ca}^{2}+$--sensitive channel currents recorded from mouse and human embryonic stem cells. J Membr Biol 246:215-230.

Soroceanu L, Manning TJ, Jr, Sontheimer H. 1999. Modulation of glioma cell migration and invasion using $\mathrm{Cl}(-)$ and $\mathrm{K}(+)$ ion channel blockers. J Neurosci 19:5942-5954.

Steinle M, Palme D, Misovic M, Rudner J, Dittmann K, Lukowski R, Ruth P, Huber SM. 201 I. lonizing radiation induces migration of glioblastoma cells by activating $\mathrm{BK} \mathrm{K}(+)$ channels. Radiother Oncol 101:122-126.

Torres YP, Granados ST, Latorre R. 2014. Pharmacological consequences of the coexpression of BK channel $\alpha$ and auxiliary $\beta$ subunits. Front Physiol 5:383.

Turner KL, Sontheimer H. 2014. Cl-and K + channels and their role in primary brain tumour biology. Philos Trans R Soc Lond B Biol Sci 369:20130095.

Wang J, Su HK, Zhao HF, Chen ZP, To SS. 2015. Progress in the application of molecular biomarkers in gliomas. Biochem Biophys Res Commun 465:I-4.

Weaver AK, Bomben VC, Sontheimer H. 2006. Expression and function of calcium-activated potassium channels in human glioma cells. Glia 54:223-233.

Weiger TM, Holmqvist MH, Levitan IB, Clark FT, Sprague S, Huang WJ, Ge P, Wang C, Lawson D, Jurman ME, Glucksmann MA, Silos-Santiago I, DiStefano PS, Curtis R. 2000. A novel nervous system beta subunit that downregulates human large conductance calcium-dependent potassium channels. J Neurosci 20:3563-3570.

Calcium-dependent potassium channels. J Neurosci 20:3563-3570.
Wondergem R, Bartley JW. 2009. Menthol increases human glioblastoma intracellular $\mathrm{Ca} 2+$, BK channel activity and cell migration. J Biomed Sci 16:90.

Wu DG, Wang YY, Fan LG, Luo H, Han B, Sun LH, Wang XF, Zhang JX, Cao L, Wang XR, You YP, Liu N. 20II. MicroRNA-7 regulates glioblastoma cell invasion via targeting focal adhesion kinase expression. Chin Med J (Engl) 124:2616-262I.

Yu SC, Bian XW. 2009. Enrichment of cancer stem cells based on heterogeneity of invasiveness. Stem Cell Rev 5:66-7I.

Zhang J, Chan YC, Ho JC, Siu CW, Lian Q, Tse HF. 2012. Regulation of cell proliferation of human induced pluripotent stem cell-derived mesenchymal stem cells via ether-à-go-go I (hEAGI) potassium channel. Am J Physiol Cell Physiol 303:CII5-CI25. 